\title{
Rapid Communication: Experimental Evidence that Juvenile Pelagic Jacks (Carangidae) Respond Behaviorally to DMSP
}

\author{
Jennifer L. DeBose • Gabrielle A. Nevitt • \\ Andrew H. Dittman
}

Received: 2 December 2009 /Revised: 19 January 2010 / Accepted: 21 January 2010/Published online: 23 February 2010

(C) The Author(s) 2010. This article is published with open access at Springerlink.com

\begin{abstract}
Dimethylsulfoniopropionate (DMSP) is produced by marine algae and released during foraging activity by zooplankton and fish. Pelagic fishes depend on patchily distributed foraging opportunities, and DMSP may be an important signaling molecule for these events. We have previously shown that the abundance of carangid jacks is positively associated with elevated DMSP levels over coral reefs in the Gulf of Mexico, suggesting that these fishes may use spatial and temporal variation in DMSP to locate foraging opportunities. Here, we extend this work by demonstrating that juveniles of two species of pelagic jack, crevalle jack, Caranx hippos, and bluefin trevally, $C$. melampygus, detect and respond to DMSP in a flowthrough tank in the laboratory. Juveniles of these species showed elevated swimming activity in response to ecologically relevant concentrations of DMSP $\left(10^{-9} \mathrm{M}\right)$. These results provide further evidence that this chemical may serve as a chemosensory cue for carangid species.
\end{abstract}

Keywords Caranx hippos · Caranx melampygus . Chemical ecology · Dimethylsulfoniopropionate (DMSP) . Foraging behavior $\cdot$ Pelagic fish $\cdot$ Sensory ecology

J. L. DeBose · G. A. Nevitt

Department of Neurobiology, Physiology and Behavior,

University of California,

Davis, CA, USA

J. L. DeBose $(\bowtie)$

Currently at the Smithsonian Marine Station,

Fort Pierce, FL, USA

e-mail: debosej@si.edu

A. H. Dittman

NOAA Fisheries-Northwest Fisheries Science Center,

Seattle, WA, USA

\section{Introduction}

Dimethylsulfoniopropionate (DMSP) is a soluble compound produced by marine algae and released during planktivorous foraging events (reviewed by Simo 2004). High DMSP concentrations are recorded in seawater around areas of high primary productivity and foraging activity, such as frontal zones or seamounts where phytoplankton tend to aggregate. Foraging aggregations often are characterized by large numbers of plankton, including phytoplankton and zooplankton, surrounded by planktivorous fishes, which are then corralled by predatory fish. Planktivorous fishes aggregate in response to DMSP (DeBose et al. 2008), and increased numbers of predatory jacks are correlated with increases in combined DMSP and dimethylsulfide (DMS) over coral reefs (DeBose and Nevitt 2007). Laboratory studies further indicated that high concentrations of DMSP $\left(10^{-2}-10^{-3} \mathrm{M}\right)$ in food increased striking frequency and weight gain in two species of saltwater fish (Nakajima et al. 1990). Predatory fishes generally are assumed to rely on visual cues. Thus, we wanted to test whether or not they can detect ecologically relevant concentrations of dissolved DMSP, with the goal of understanding the use of chemical cues in driving foraging events, and ultimately, trophic cascades. Specifically, the aim of the current study was to use a simple behavioral assay to verify whether jacks can detect DMSP.

\section{Methods and Materials}

Experimental Animals We tested behavioral responses of juveniles of two species of jack, crevalle jack, Caranx hippos, and bluefin trevally, C. melampygus, to DMSP by using a flow-through Plexiglas tank (Hara 2006). Crevalle jack are reef-associated pelagic, schooling fish from the 
Atlantic Ocean, and bluefin trevally are a commercially important Pacific Ocean species. Adult crevalle jack and bluefin trevally feed mostly on fish and crustaceans (Lieske and Myers 2001), although at the juvenile stage we tested, both species feed on plankton.

Juvenile bluefin trevally [ 2-mo-old; size range: $45.65-$ $82.15 \mathrm{~mm}$ total length (TL)] were hatched and originally reared at the Oceanic Institute (Waimanalo, HI, USA), and then transported to the Northwest Fisheries Science Center, NOAA-Fisheries, Mukilteo Research Station, Mukilteo, WA, USA, for this study. Fish were housed in circular tanks (1.3-2.0 m diam.) supplied with sand-filtered flowthrough seawater $\left(21-23^{\circ} \mathrm{C}\right)$. Juvenile crevalle ( 1-2-mo-old; $57.30-72.80 \mathrm{~mm} \mathrm{TL})$, associated with Sargassum mats, Sargassum natans, were collected near Galveston, TX, USA, and held in rectangular seawater tanks $(1.8 \times 0.8 \times$ $0.7 \mathrm{~m}$ ) at the Moody Gardens Aquarium Quarantine facility in Galveston, TX, USA.

Flow Tank Specifications All experiments were conducted in a 511 flow-through tank $(157 \times 30 \times 14 \mathrm{~cm})$ with a flow rate of 5-7 1/min and a water depth of $10.8 \mathrm{~cm}$. Water flow was smoothed by a flow-straightener (FS) made of straws (length: $9 \mathrm{~cm}$; diam: $1.1 \mathrm{~cm}$ ) glued together to form a 'honeycomb' of channels, located $10 \mathrm{~cm}$ downstream from the intake. Stimuli were introduced into the tank upstream of the FS, where an airstone thoroughly mixed the injected stimuli prior to flowing into the experimental arena of the tank. An airstone is a piece of porous stone whose purpose is to gradually diffuse oxygen into aquaria, thus eliminating the noise and large bubbles of conventional air filtration systems. The entire tank was housed under black plastic to reduce visual cues, but the tank was illuminated by infrared lights to allow recording of fish movements with an infrared camera (Sony DCR-TRV-17).

Testing Protocol Behavioral trials for DMSP responses were conducted from June to September 2006 with a total of 10 crevalle and 8 bluefin trevally. Prior to each trial, a single fish was fasted for $24 \mathrm{~h}$ and then placed in the downcurrent end of the flow table for an $8 \mathrm{~h}$ acclimation period. After acclimation, fish movement patterns along the length of the flow table (see Behavioral Scoring and Analysis below) were recorded for $10 \mathrm{~min}$ immediately prior to stimulus release (DMSP or ASW). Stimulus water was metered into the flow table for $1 \mathrm{~min}$, and behavior was recorded for an additional $10 \mathrm{~min}$. After a $30 \mathrm{~min}$ recovery period, the process was repeated with the second stimulus. In pilot studies, $30 \mathrm{~min}$ was sufficient for the experimental stimulus to vacate the tank and fish to resume background levels of activity. Fish were used in only one trial, experiencing both stimuli. The order of stimulus delivery was switched every trial.
Chemical Stimuli Two stimuli were tested during each trial: $10^{-9} \mathrm{M}$ DMSP and artificial saltwater (ASW, Instant Ocean $^{\circledR}$, Mentor, OH, USA). ASW or DMSP $(1.0 \times$ $\left.10^{-7} \mathrm{M}\right)$ were delivered via intravenous medical bags positioned outside the black plastic blind. Stimuli were injected at a rate of $60 \mathrm{ml} / \mathrm{min}$ into the pre-FS reservoir for $1 \mathrm{~min}$. Complete mixing, confirmed by dye release studies (Bright Dyes ${ }^{\circledR}$, Miamisburg, OH, USA), yielded a final concentration of $1.0 \times 10^{-9} \mathrm{M}$ DMSP in the reservoir. This concentration is within the natural range of DMSP measured over coral reefs (Jones et al. 2007: 0.43-27 nM). DMSP solutions were prepared in artificial saltwater (ASW) matched to background salinity $( \pm 1 \mathrm{ppt})$ with a YSI meter (MODEL 85, YSI Inc., Yellow Springs, OH, USA). Working DMSP solutions were prepared immediately before each trial from stock solutions of DMSP $\left(10^{-3} \mathrm{M}\right)$ (Chemische Laboratoria, Rijksuniversiteit Groningen, Groningen, The Netherlands) stored at $-20^{\circ} \mathrm{C}$. All solutions were equilibrated to background water temperature $\left(22.0 \pm 0.10^{\circ} \mathrm{C}\right.$ for bluefin trevally, $26.8 \pm 0.11^{\circ} \mathrm{C}$ for crevalle jack) before each experimental trial.

Behavioral Scoring and Analysis Recorded trials were scored with J-Watcher software (V1.0, Macquarie Univer-

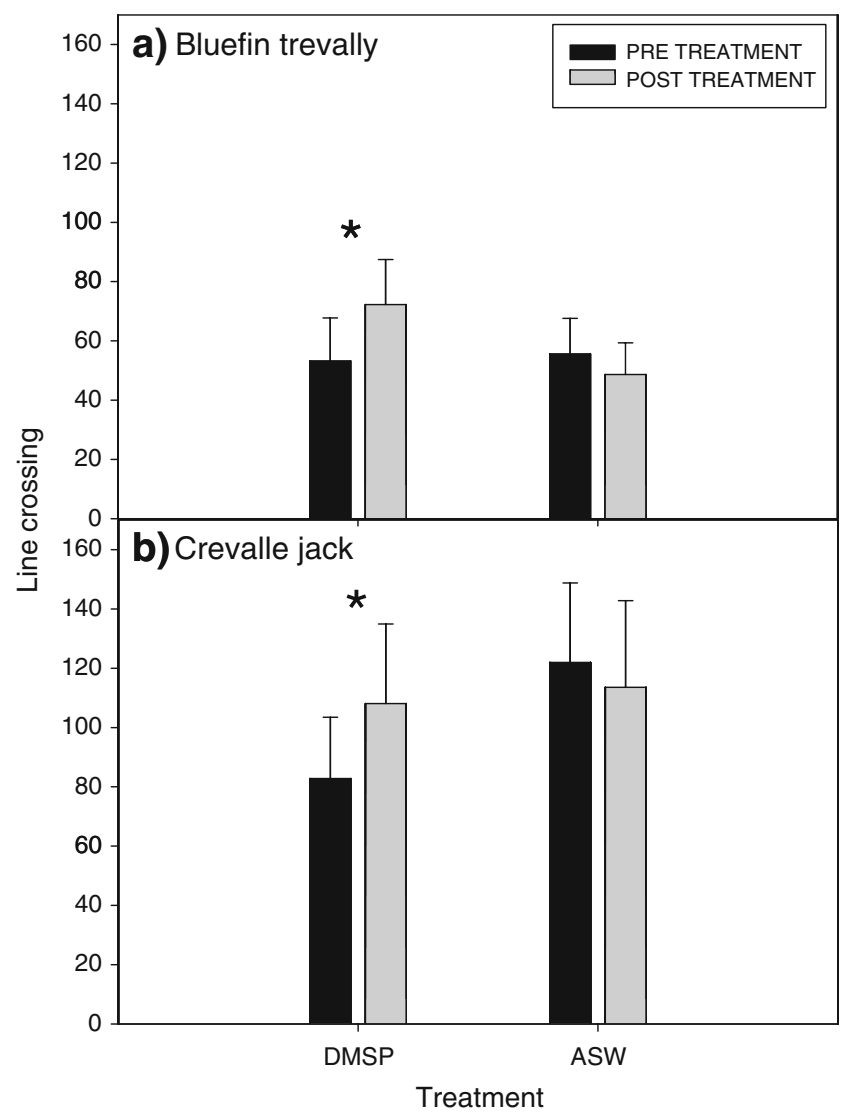

Fig. 1 Bluefin trevally (a) and crevalle jack behavioral response (b) to artificial salt water (ASW) and $10^{-9} \mathrm{M}$ DMSP. Asterisk denotes significant difference in line crossing behavior between time periods associated with pre- (black bar) and post- (gray bar) treatment stimuli 
sity and UCLA) by an observer blind to the treatment. The responses before and after stimuli exposure were defined as the number of lines crossed $10 \mathrm{~min}$ before and $10 \mathrm{~min}$ after stimuli presentation. The number of lines crossed was determined by using $10 \mathrm{~cm}$ grid lines on the bottom of the tank. Line crossings were defined by the entire head of the fish crossing the grid line. Data (before/after responses) were analyzed by paired $t$-test $(\alpha=0.05)$ with beforestimulus responses as individual controls.

\section{Results and Discussion}

Both bluefin trevally and crevalle jack increased their number of line crosses in response to $10^{-9} \mathrm{M}$ DMSP but not ASW (bluefin trevally: Fig. 1a, DMSP: $P<0.01$; ASW: $P=0.28, N=8$; crevalle: Fig. 1b, DMSP: $P<0.05$; ASW: $P=0.71, N=10$ ). Pre-stimulus activity levels were similar for both DMSP and ASW (bluefin trevally: $P=0.901$; crevalle: $P=0.353$ ), with fish moving throughout the test arena during the pre-stimulus period. Results indicate that Caranx spp. detected $10^{-9} \mathrm{M}$ DMSP in a laboratory setting.

The ability to detect DMSP could be advantageous in finding food and/or habitat under laboratory and natural conditions; by increasing activity in the presence of this compound, jacks could use DMSP to locate foraging opportunities. DMSP was present in the commercial feeds fed to these jacks $\left(2.7-3.1 \times 10^{-7} \mathrm{M}\right.$ (extract); DeBose 2008) and wild crevalle jack used in these studies were captured under Sargassum mats, which also produce DMSP (Broadbent et al. 2002). In previous studies, we measured concentrations of total DMSP over coral reefs in the Gulf of Mexico and Caribbean (DMSPt, dissolved + particulate: $10^{-8}-10^{-9} \mathrm{M}$; DeBose and Nevitt 2007; DeBose 2008). Dissolved DMSP concentrations in the waters over the Great Barrier Reef are reported to be in the $10^{-7}-10^{-9} \mathrm{M}$ range (Broadbent et al. 2002; Jones et al. 2007).

Our results provide evidence that two species of carangid jack detect ecologically relevant concentrations of DMSP, thus supporting the hypothesis that this compound, released during feeding interactions, might be an effective sensory cue for these fish in their natural environments. Overall, however, we are only beginning to understand the role of DMSP as a signal molecule in marine ecosystems. This study, combined with previous work (Nakajima et al. 1990; DeBose and Nevitt 2007; DeBose et al. 2008), provides intriguing evidence that pelagic fishes detect DMSP and may use this algal-produced compound as a foraging or habitat-associated cue in their natural environment. Reef-associated jacks must find habitat and foraging opportunities as they range over the reef and beyond into blue water, and most likely they use a suite of chemical and other sensory cues for orientation. By cueing to the release of DMSP associated with foraging activities of zooplankton and planktivorous fishes (Hill and Dacey 2006; DeBose et al. 2008), pelagic jacks could use this chemical to locate transient and localized foraging opportunities. The role of chemical cues in the behavior of pelagic fishes such as jacks is only beginning to be recognized. Although this study implicates DMSP as a compound of interest, others (e.g., amino acids, amines, etc.; Hara 2006) also are known feeding stimuli. Further work is needed to fully understand the multitude of ways that these fish may use chemical compounds to forage and navigate in their marine environment.

Acknowledgments We thank the Oceanic Institute, specifically C. Laidley and staff, for providing bluefin trevally. We also thank P. Swanson, M. Havey, D. May, M. Rust, T. Scott, P. Plesha, and F. Sommers, of the Northwest Fisheries Science Center, NOAA, for help in acquiring and maintaining trevally. Thanks to Moody Gardens Aquarium, especially R. Drinnen, B. Christie and staff, B. Dailey, and M. Weber, for collecting and housing crevalle jacks. We also thank S. Strom (Shannon Point Marine Center) for GC use. Experiments were conducted under UCD ACUC \#12050. Funding was provided by a PEO Scholar Award and by a NSFGRF (JLD) and by a grant from NOAA Fisheries (AHD).

Open Access This article is distributed under the terms of the Creative Commons Attribution Noncommercial License which permits any noncommercial use, distribution, and reproduction in any medium, provided the original author(s) and source are credited.

\section{References}

BroAdBent, A., JonEs, G. B., and JONES, R. J. 2002. DMSP in corals and benthic algae from the Great Barrier Reef. Est. Coast. Shelf Sci. 55:547-555.

DeBose, J. L. 2008. Investigating the role of dimethylsulfoniopropionate (DMSP) as an aggregation cue for coral reef and reef-associated fishes. Ph.D. dissertation. University of California.

DeBose, J. L. and NeVITT, G. A. 2007. Investigating the association between pelagic fish and DMSP in a natural coral reef system. Mar. Freshw. Res. 58:720-724.

Debose, J. L., Lema, S. C., and NevitT, G. A. 2008. Dimethylsulfoniopropionate (DMSP) as a foraging cue for reef fishes. Science 319:1356.

HARA, T. J. 2006. Feeding behaviour in some teleosts is triggered by single amino acids primarily through olfaction. J. Fish Biol. 68:810-825.

HILL, R. W. and DACEY, J. W. H. 2006. Metabolism of dimethylsulfoniopropionate (DMSP) by juvenile Atlantic menhaden Brevoortia tyrannus. Mar. Ecol. Prog. Ser. 322:239-248.

Jones, G. B., Curran, M., Broadbent, A., King, S., Fischer, E., and JONES, R. 2007. Factors affecting the cycling of dimethylsulfide and dimethylsulfoniopropionate in coral reef waters of the Great Barrier Reef. Environ. Chem. 4:310-322.

Lieske, E. and Myers, R. 2001. Coral Reef Fishes: Indo-Pacific and Caribbean, p. 400. Princeton University Press, New Jersey.

NAKAJIMA, K., UCHIDA, A., and IsHIDA, Y. 1990. Effect of a feeding attractant, dimethyl- $\beta$-propiothetin, on growth of marine fish. Nipp. Suis. Gakk. 56:1151-1154.

SimO, R. 2004. From cells to globe: approaching the dynamics of DMS(P) in the ocean at multiple scales. Can. J. Fish. Aquat. Sci. 61:673-684. 